\title{
Effects of Alcohol Addition on Gelation in Aqueous Solution of Poly(ethylene oxide)-Poly(propylene oxide)-Poly(ethylene oxide) Triblock Copolymer
}

\author{
Kwan-Wook KwoN, Moon Jeong PARK, Jiyoung HwANG, and Kookheon CHAR ${ }^{\dagger}$ \\ School of Chemical Engineering, Seoul National University, \\ San 56-1, Shinlim-dong, Kwanak-gu, Seoul 151-744, Korea
}

(Received October 25, 2000; Accepted Junuary 24, 2001)

\begin{abstract}
The effects of alcohol addition on gelation and micellization in aqueous solution of $\mathrm{EO}_{100} \mathrm{PO}_{65} \mathrm{EO}_{100}$ (Pluronic F127) triblock copolymer were studied using tube inversion method (TIM), rheometry, dynamic light scattering (DLS), and high sensitive differential scanning calorimetry (DSC). Upon the addition of alcohol such as methanol or ethanol, the hard gel transition temperature is raised resulting in reduced hard gel region in the phase diagram and these alcohols were shown to increase the critical micelle temperature $(\mathrm{cmt})$. Butanol, however, clearly lowers hard gel transition temperature and cmt. In the case of propanol up to $15 \mathrm{v} \%$ the onset temperature of the hard gel is slightly lowered while the hard gel transition temperature is raised for propanol content more than 20 v\%. The experimental investigation shows that lower alcohols such as methanol and ethanol prevent the onset of gelation and micellization while higher alcohols such as butanol favor gelation as well as the formation of micelles in aqueous solution of $\mathrm{EO}_{100} \mathrm{PO}_{65} \mathrm{EO}_{100}$ triblock copolymer.
\end{abstract}

KEY WORDS Poly(ethylene oxide)-Poly(propylene oxide)-Poly(ethylene oxide) Triblock Copolymer /

Alcohol Effect / Hard Gel Transition / Micellization /

Numerous studies have been devoted to aqueous solutions of poly(ethylene oxide)-poly(propylene oxide)-poly(ethylene oxide) (PEO-PPO-PEO) triblock copolymers using experimental techniques such as small angle neutron scattering (SANS), ${ }^{1-5}$ small angle X-Ray scattering (SAXS), ${ }^{6,7}$ fluorescence, ${ }^{8,9}$ differential scanning calorimetry, ${ }^{10,11}$ static and dynamic light scattering, ${ }^{12,13}$ and rheological measurement. ${ }^{10,14,15}$ These copolymers are commercially available as surfactants (Pluronics ${ }^{\circledR}$; BASF or Poloxamers ${ }^{\circledR}$; ICI) and widely used for emulsification, detergency, dispersion stabilization and so forth. ${ }^{16}$

Because of the amphiphilic character of the PEO-PPOPEO triblock copolymer, it forms spherical micelles ${ }^{6,17}$ due to its self-assembling nature in aqueous solution when its solution concentration exceeds the critical micelle concentration $(\mathrm{cmc})^{8,14,18}$ or solution temperature is increased above the critical micelle temperature (cmt). ${ }^{5,8,18}$

In aqueous solutions of $\mathrm{EO}_{100} \mathrm{PO}_{65} \mathrm{EO}_{100}$ (Pluronic F127) sol-to-gel and gel-to-sol transition is observed as temperature is increased at copolymer concentrations as low as $20 \mathrm{wt} \%$. $^{6,15,18,19}$ Gels formed with this triblock copolymer are physical gels formed through non-covalent associations and gels reversibly transform to sols when the temperature is lowered below the gelation temperature namely thermoreversible gelation. ${ }^{15,18}$

Several mechanisms of thermally reversible gelation of the $\mathrm{EO}_{100} \mathrm{PO}_{65} \mathrm{EO}_{100}$ copolymer solution have been proposed. The sol-to-gel transition has been explained in terms of intrinsic change in micellar properties ${ }^{20}$ or entropic change associated with locally ordered water molecules close to the PPO hydrophobic blocks. ${ }^{21}$ SANS experiments showed that the gel transition is due to hard-sphere crystallization when the micelle concentration reaches the critical volume fraction of $0.53 .^{3}$ This implies that gels form when the micelles are arranged in a close-packed (cubic) array of micelles. ${ }^{1,15}$ With increasing solution temperature and concentration of the $\mathrm{EO}_{100^{-}}$ $\mathrm{PO}_{65} \mathrm{EO}_{100}$ triblock copolymer, the average number of polymer chains per micelle (i.e., aggregation number) increases because the unimer-micelle equilibrium shifts further toward the micelle state, but after the aggregation number reaches a plateau value average distance between micelles is reduced due to increase in micelle concentration and eventually the micelles touch one another. ${ }^{3}$ This causes entanglements of hydrophilic corona PEO chains of micelles and also has a possibility of forming a local crystalline structure. ${ }^{3}$ Strong entanglements among the corona chains form hard gels ${ }^{22}$ while weak entanglements yield soft gels ${ }^{10,22}$ whose storage modulus $\left(G^{\prime}\right)$ is generally about ten times smaller than the storage modulus $\left(G^{\prime}\right)$ of the hard gel. Further increase in temperature causes gel-to-sol transition because water acts as a poor solvent of corona PEO chains, collapsing in solution and eventually precipitating as the Flory $\Theta$ temperature of PEO is approached. ${ }^{3,22}$

There are many factors which affect the formation of micelles and gels including crystallinity, ${ }^{3}$ molecular characteristics such as PPO/PEO ratio and molecular weight, ${ }^{8,14}$ and additives ${ }^{23}$ such as salts. ${ }^{17}$ However, the effects of alcohol addition on the sol-to-gel transition behavior of PEO-PPO-PEO triblock copolymers have not been investigated in detail except for a few initial works. ${ }^{24-27}$ Few studies address change in thermodynamics of an aqueous PEO-PPO-PEO system (i.e., phase diagram) upon the addition of alcohol and its effects on macroscopic properties such as rheological behavior,

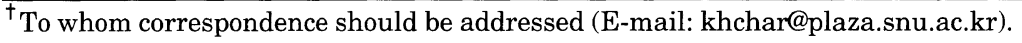


which is quite sensitive to local structural change. The present study investigates the effects of alcohol addition on sol-to-gel transition of aqueous $\mathrm{EO}_{100} \mathrm{PO}_{65} \mathrm{EO}_{100}$ triblock copolymer solutions and more specifically, effects on rheological properties.

\section{EXPERIMENTAL}

\section{Materials}

Commercial grade $\mathrm{EO}_{100} \mathrm{PO}_{65} \mathrm{EO}_{100}$, Pluronic F127, was kindly donated by BASF and used without further purification. The nominal molecular weight of this copolymer is 12600 and weight fraction of PEO in the triblock copolymer is approximately $70 \%$.

Four alcohols with different degrees of hydrophobicitymethanol, ethanol, $n$-propanol, and $n$-butanol were used. The boiling points of the alcohols are $65.0^{\circ} \mathrm{C}$ for methanol, $78.5^{\circ} \mathrm{C}$ for ethanol, $97.4^{\circ} \mathrm{C}$ for $n$-propanol, and $117.3^{\circ} \mathrm{C}$ for $n$-butanol, respectively.

\section{Preparation of Samples}

Aqueous solutions of the $\mathrm{EO}_{100} \mathrm{PO}_{65} \mathrm{EO}_{100}$ triblock copolymer at various concentrations ( $\mathrm{wt} \%$ ) were prepared and heated to $90^{\circ} \mathrm{C}$ for $10 \mathrm{~min}$ in sealed vials. The solutions were gently agitated and stored below $5^{\circ} \mathrm{C}$ for more than 1 day.

Mixtures of alcohol and distilled water at various volume ratios of alcohol to water [v(alcohol)/v(water); 5/95, $10 / 90,15 / 85,20 / 80,25 / 75,30 / 70,40 / 60]$ were used as mixed solvents for the triblock copolymer and polymer concentrations of these solutions were fixed at $20 \mathrm{wt} \%$ because it was expected that the effect of alcohol addition would be much more pronounced with $20 \mathrm{wt} \%$ polymer concentration since only a hard-gel was observed with this concentration in pure water. The triblock copolymer and mixed solvent were weighed into a tightly sealed vial and incubated below $5^{\circ} \mathrm{C}$ for more than 2 days without stirring to prevent evaporation of the low boiling alcohol.

\section{Tube Inversion Method}

Vials with diameter of $13 \mathrm{~mm}$ were used, sealed with Teflon tape are placed in a water bath to control temperature with an accuracy of $\pm 0.01^{\circ} \mathrm{C}$. To ensure equilibrium, more than $10 \mathrm{~min}$ temperature equilibration time was allowed for each temperature and measurements were carried out every $0.5^{\circ} \mathrm{C}$ from $1{ }^{\circ} \mathrm{C}$ to $90^{\circ} \mathrm{C}$. Change from a mobile state to an immobile one was determined by inverting the vial. Hard gels were defined as immobility of the solution (i.e., no movement of the liquid meniscus in the vial for more than $5 \mathrm{~min}$ ) while soft gels were defined as detection of any slow movement of the meniscus over a period of $5 \mathrm{~min}$. Sols were defined as those that readily flow to the bottom of a tube within 5 min upon inversion.

\section{Rheology}

A Rheometer RMS-800 (Rheometrics, Inc.) in a conicylinder geometry (cup diameter, $52 \mathrm{~mm}$; bob diameter, $50 \mathrm{~mm}$; bob length, $20 \mathrm{~mm}$; and bottom gap, $0.2 \mathrm{~mm}$ ) was used to measure the dynamic viscoelastic storage modulus $G^{\prime}$ and loss modulus $G^{\prime \prime}$ of $\mathrm{EO}_{100} \mathrm{PO}_{65} \mathrm{EO}_{100}$ solutions as a function of temperature. Temperature scans at a fixed frequency of $0.5 \mathrm{rad} \mathrm{s}^{-1}$ were carried out at a heating rate of $1^{\circ} \mathrm{C} \mathrm{min}^{-1}$ from $2^{\circ} \mathrm{C}$ to $90^{\circ} \mathrm{C}$. Strain was fixed at $2.7 \%$ which was small enough to ensure linear viscoelasticity.

\section{Dynamic Light Scattering (DLS)}

BI-9000AT (Brookkaven, Inc.) was used to detect size distribution of $\mathrm{EO}_{100} \mathrm{PO}_{65} \mathrm{EO}_{100}$ in water. DLS is equipped with a digital autocorrelator and photon counter. Light source of a $\mathrm{He}-\mathrm{Ne}$ laser with $\lambda=632.8$ $\mathrm{nm}$ was used and scattering angle was fixed at $90^{\circ}$. Inverse Laplace transform was performed using the CONTIN program. All solutions were again filtered with filters of $0.45 \mu \mathrm{m}$ pore size to avoid effects of impurity.

\section{Differential Scanning Calorimeter (DSC)}

A Hart DSC (Model 4110; Calorimetry Sciences Corp.) was used to measure cmt of $\mathrm{EO}_{100} \mathrm{PO}_{65} \mathrm{EO}_{100}$ copolymer solution in a temperature range between $0^{\circ} \mathrm{C}$ and $80^{\circ} \mathrm{C}$. This DSC has high sensitivity to detect a tiny amount of heat flow even up to $\mu \mathrm{cal} \mathrm{g}^{-1}$. The concentration of the triblock copolymer solution was fixed at $0.3 \mathrm{wt} \%$ and the heating rate was fixed at $1^{\circ} \mathrm{C} \mathrm{min}^{-1}$. Samples were sealed in steel cylinders and an empty cylinder was used as reference. All solutions were filtered with $0.45 \mu \mathrm{m}$ pore size filters to avoid effects of impurity.

\section{RESULTS AND DISCUSSION}

The effects of alcohol addition to the aqueous solutions of $\mathrm{EO}_{100} \mathrm{PO}_{65} \mathrm{EO}_{100}$ (Pluronic F127) were investigated at various volume ratios of alcohol to water $(5-40 \mathrm{v} \%)$ for methanol, ethanol, propanol, and butanol. Figure 1 shows the phase diagram of the triblock copolymer in pure water and schematic structures of sol, soft gel, and hard gel are illustrated. The $\mathrm{EO}_{100} \mathrm{PO}_{65} \mathrm{EO}_{100}$ triblock copolymer exists as a unimer ${ }^{6}$ below $\mathrm{cmc}$ or $\mathrm{cmt}$. Above cmc or cmt the triblock copolymer forms spherical micelles consisting of PPO as core and PEO as corona. ${ }^{6,17}$ The number of micelles increases with solution temperature or concentration of $\mathrm{EO}_{100} \mathrm{PO}_{65} \mathrm{EO}_{100}$ triblock copolymer. Further increase of temperature or concentration makes micelles overlap. ${ }^{3}$ Weak entanglement among corona PEO chains generally forms soft gels ${ }^{10,22}$ while

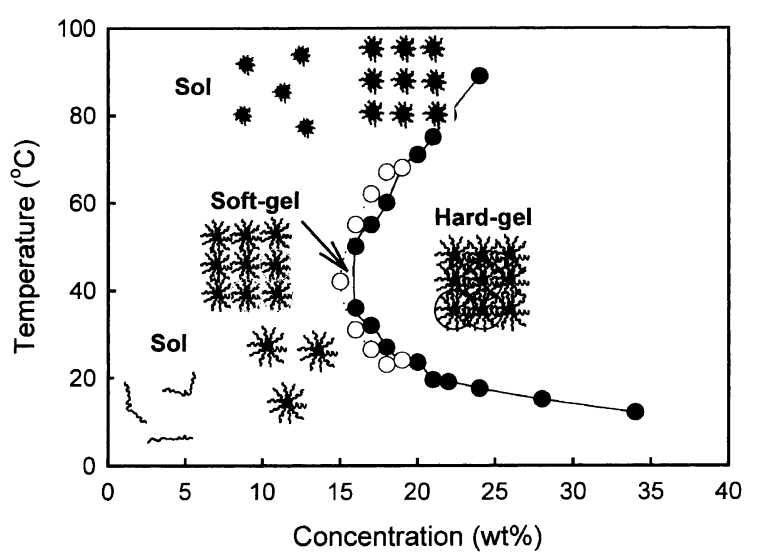

Figure 1. Phase diagram of $\mathrm{EO}_{100} \mathrm{PO}_{65} \mathrm{EO}_{100}$ in water made with the tube inversion method (TIM). Closed circles $(\mathbf{O})$ are the hard gel boundaries and open circles $(\bigcirc)$ show the soft gel boundaries. 
strong entanglements yield hard gels. ${ }^{22}$ At even high temperature gel-to-sol transition occurs because water acts as a poor solvent of corona PEO chains, shrinking to the core. ${ }^{3}$ Hard gels are observed for copolymer concentrations above $16 \mathrm{wt} \%$ within a temperature between $10^{\circ} \mathrm{C}$ and $90^{\circ} \mathrm{C}$ in agreement with previously reported results. ${ }^{17,18,28}$ For copolymer concentrations from 15 to 19 wt\% soft gels are also observed around the hard gel boundary, as detected by the tube inversion method (TIM).

In the addition of ethanol to $\mathrm{EO}_{100} \mathrm{PO}_{65} \mathrm{EO}_{100}$ aqueous solution, hard gel boundaries shift toward higher polymer concentrations with increase in ethanol volume fraction, as shown in Figure 2. Because the boiling point of ethanol is $78.5^{\circ} \mathrm{C}$, the phase diagram in Figure 2 is limited to the temperature of $78.5^{\circ} \mathrm{C}$. The addition of ethanol suppresses the formation of hard gels and this is even more pronounced with a larger amount of ethanol. As the hard gel boundaries shift toward higher polymer

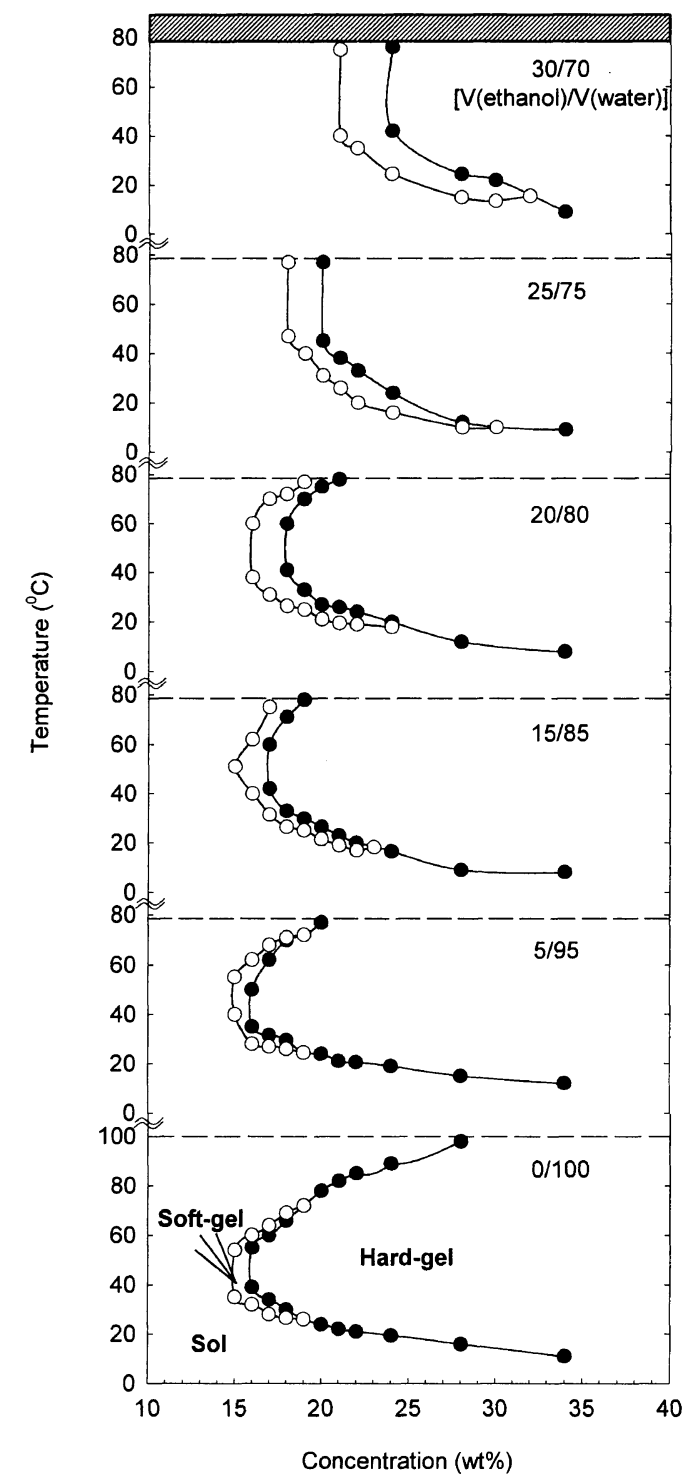

Figure 2. Phase diagram of $\mathrm{EO}_{100} \mathrm{PO}_{65} \mathrm{EO}_{100}$ in a mixed solvent of ethanol and water made with the tube inversion method (TIM). Closed circles $(O)$ are hard gel boundaries and open circles $(\bigcirc)$ show soft gel boundaries. Measuring temperature is limited to $78.5^{\circ} \mathrm{C}$ due to the boiling point of ethanol. concentrations with the addition of ethanol, the soft gel boundaries move to higher polymer concentrations. The soft gel boundary shifts less in comparison with the shift of the hard gel boundary. As a result, the soft gel region expands with increase in ethanol volume ratio (Figure 2 ). We believe that a region in which a hard gel initially forms and is converted to a soft gel region due to ethanol addition, presumably hindering the close packing of the block copolymer micelles.

For a $20 \mathrm{wt} \%$ aqueous solution of the $\mathrm{EO}_{100} \mathrm{PO}_{65} \mathrm{EO}_{100}$ triblock copolymer, Figure 3 shows rheological properties such as storage modulus $\left(G^{\prime}\right)$, loss modulus $\left(G^{\prime \prime}\right)$, complex viscosity $\left(\eta^{*}\right)$, and $\tan \delta$ measured as a function of temperature with a heating rate of $1^{\circ} \mathrm{C} \min ^{-1}$. At that concentration, aqueous solution of the $\mathrm{EO}_{100} \mathrm{PO}_{65^{-}}$ $\mathrm{EO}_{100}$ triblock copolymer undergoes sol-to-hard gel and hard gel-to-sol transition as temperature is increased, as previously shown in Figure 1 . The crossover point, defined as $G^{\prime}=G^{\prime \prime}$, has been proposed as a criterion for the sol-to-gel transition ${ }^{29}$ and this criterion has been discussed in previous studies. ${ }^{10,30}$ In our work, abrupt changes in moduli were defined as sol-to-hard gel transition $^{22}$ and this criterion was in excellent agreement with the results obtained with TIM.

Rheological properties of the $20 \mathrm{wt} \% \mathrm{EO}_{100} \mathrm{PO}_{65} \mathrm{EO}_{100}$ copolymer solution were measured at different volume ratios of alcohol to water $(0-40 \mathrm{v} \%)$ for various alcohols. The effect of alcohol addition can be more clearly observed with $20 \mathrm{wt} \%$ solution since only the hard gel, whose storage modulus $\left(G^{\prime}\right)$ reaches $10^{4} \mathrm{~Pa}$, was formed with this concentration in pure water. The hard gel transition can be easily detected by abrupt changes in storage modulus $\left(G^{\prime}\right)$ but the soft gel transition cannot be unequivocally detected because $G^{\prime}$ gradually increases with temperature in the coni-cylinder geometry before abrupt jump to a hard gel. For alcohols with shorter alkyl chains such as methanol and ethanol, the hard gel transition temperature initially shifted to a higher temperature with the addition of a small amount of the alcohol as shown in Figures $4 \mathrm{a}$ and $4 \mathrm{~b}$. The degree of shift of the hard gel boundary was small within a temperature range of $5^{\circ} \mathrm{C}$ for methanol $(5,10,15 \mathrm{v} \%)$ and for ethanol $(5,10,15,20 \mathrm{v} \%)$. When more methanol or ethanol, the hard gel transition temperature significantly shifted to a higher temperature; for $25 \mathrm{v} \%$ and $30 \mathrm{v} \%$ of methanol

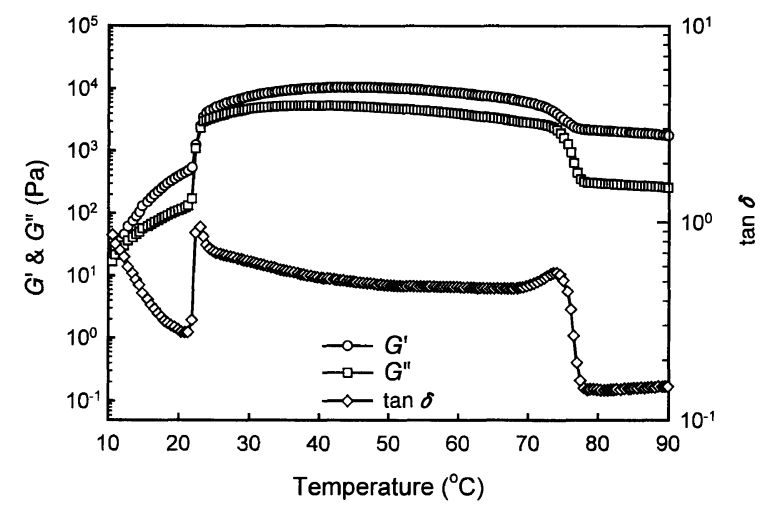

Figure 3. Storage modulus $\left(G^{\prime}\right)$, loss modulus $\left(G^{\prime \prime}\right)$, and $\tan \delta$ plotted against temperature for a $20 \mathrm{wt} \%$ aqueous solution of $\mathrm{EO}_{100} \mathrm{PO}_{65} \mathrm{EO}_{100}$ copolymer. Heating rate is $1^{\circ} \mathrm{C} \mathrm{min}^{-1}$. 

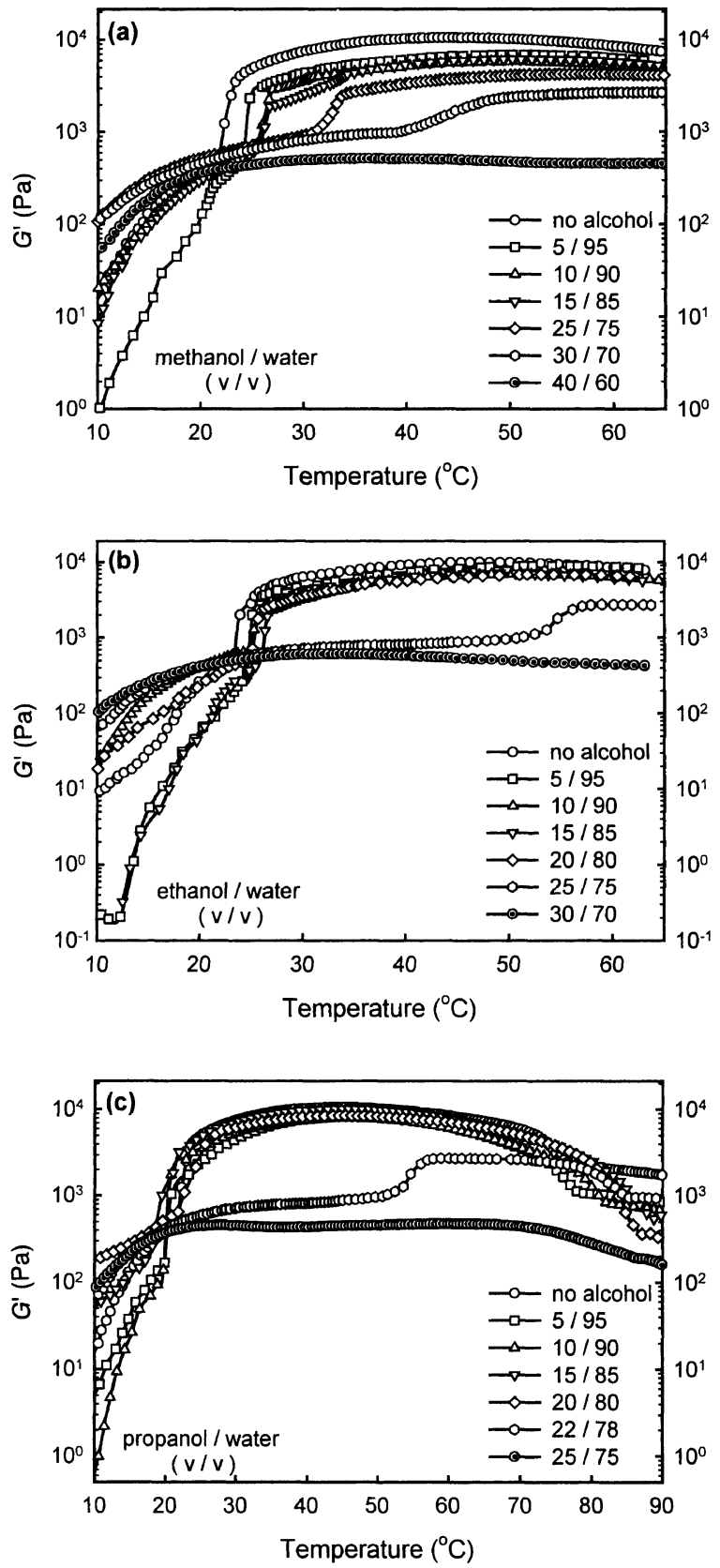

Figure 4. Changes of storage modulus $\left(G^{\prime}\right)$ as a function of temperature at different volume fractions of alcohol in water; for (a) methanol, (b) ethanol, and (c) propanol. The concentration of $\mathrm{EO}_{100} \mathrm{PO}_{65} \mathrm{EO}_{100}$ copolymer solution is fixed at $20 \mathrm{wt} \%$ and the heating rate is $1^{\circ} \mathrm{C} \mathrm{min}^{-1}$.

the hard gel transitions shifted from $23.5^{\circ} \mathrm{C}$ to $33.5^{\circ} \mathrm{C}$ and $47^{\circ} \mathrm{C}$, respectively and for $25 \mathrm{v} \%$ of ethanol the hard gel transition shifted from $23.5^{\circ} \mathrm{C}$ to $55^{\circ} \mathrm{C}$. When more than $40 \mathrm{v} \%$ methanol and $30 \mathrm{v} \%$ ethanol were added to aqueous copolymer solution, there were no abrupt changes in $G^{\prime}$ as a function of temperature and $G^{\prime}$ remained relatively low $\left(G^{\prime}<10^{3} \mathrm{~Pa}\right)$. This implies that in the case of the addition of alcohols with shorter alkyl chain $\left(\mathrm{C}_{1}\right.$ and $\left.\mathrm{C}_{2}\right)$ the formation of hard gels may be strongly affected by the addition of large amounts of alcohols with short alkyl groups.

In the case of propanol, the effect of alcohol addition on the gelation is unique because propanol is marginal in the alkyl chain length between ethanol and butanol.
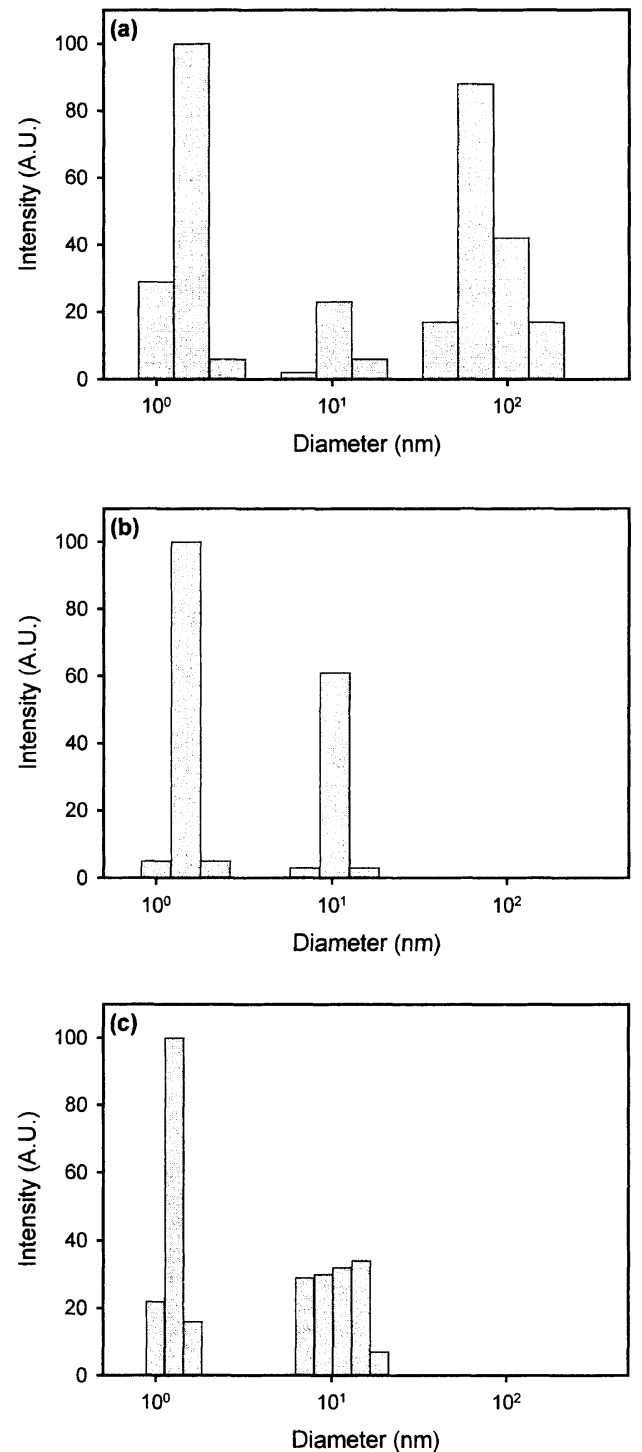

Figure 5. Size distribution, determined by dynamic light scattering, of unimers, micelles, and clusters of micelles for $20 \mathrm{wt} \%$ of $\mathrm{EO}_{100} \mathrm{PO}_{65} \mathrm{EO}_{100}$ at $15^{\circ} \mathrm{C}$ in (a) pure water, (b) ethanol/water (v/v; $25 / 75)$, and (c) propanol/water (v/v; 25/75).

As shown in Figure 4c the onset temperature of the hard gel slightly shifted to a lower temperature for $5 \mathrm{v} \%, 10$ $\mathrm{v} \%$, and $15 \mathrm{v} \%$ propanol addition while the temperature of the hard gel transition was raised to $24^{\circ} \mathrm{C}$ and $55^{\circ} \mathrm{C}$ upon the addition of $20 \mathrm{v} \%$ and $22 \mathrm{v} \%$ propanol, respectively. When propanol was added above $25 \mathrm{v} \%$, no hard gel transition was observed.

The effect of the addition of a large amount of ethanol and propanol was investigated using dynamic light scattering (DLS) as shown Figure 5. For a $20 \mathrm{wt} \%$ aqueous solution of $\mathrm{EO}_{100} \mathrm{PO}_{65} \mathrm{EO}_{100}$ triblock copolymer at $15^{\circ} \mathrm{C}$, unimers $(1-3 \mathrm{~nm})$, micelles $(10-20 \mathrm{~nm})$, and clusters of micelles $(40-170 \mathrm{~nm})$ were observed. When $25 \mathrm{v} \%$ ethanol or propanol was added to the copolymer solution at $15^{\circ} \mathrm{C}$, only the motion of unimers and micelles was detected. This points toward the suppression of cluster formation of micelles, eventually related to the suppression of gelation.

In contrast to alcohols with shorter alkyl chains, an alcohol with a longer alkyl chain such as butanol has fa- 
vorable effect on gelation. When butanol content in the water/butanol mixed solvent reaches $10 \mathrm{v} \%$, the gel boundary moves to a lower block copolymer concentration as well as to a lower temperature in the phase diagram expanding the hard gel region, as shown in Figure 6a. This is more clearly seen in rheological behavior. For a $20 \mathrm{wt} \% \mathrm{EO}_{100} \mathrm{PO}_{65} \mathrm{EO}_{100}$ copolymer dissolved in mixed solvents containing $5 \mathrm{v} \%$ and $10 \mathrm{v} \%$ of butanol in water, the sol-to-hard gel transition changes from $23.5^{\circ} \mathrm{C}$ in pure water to $19.5^{\circ} \mathrm{C}$ and $11^{\circ} \mathrm{C}$, respectively, as shown in Figure $6 \mathrm{~b}$. The sol-to-hard gel boundary eventually disappears when a large amount of butanol is added to aqueous solution of copolymer $(30 \mathrm{v} \%$ butanol in Figure $6 b)$.

These differences of the addition of alcohols in gelation behavior were found in the measurement of the critical micelle temperature $(\mathrm{cmt})$. With the addition of alcohols with shorter alkyl chains such as methanol and ethanol, cmt increases with volume fraction of alcohol in water, as shown in Figures $7 \mathrm{a}$ and $7 \mathrm{~b}$. Such shift in $\mathrm{cmt}$ indicates that the formation of micelles is suppressed upon the addition of shorter alcohols (i.e., methanol and ethanol) and decrease in the heat of endotherm with alcohol content points to the fact that the number of micelles formed gradually decreases with the amount of
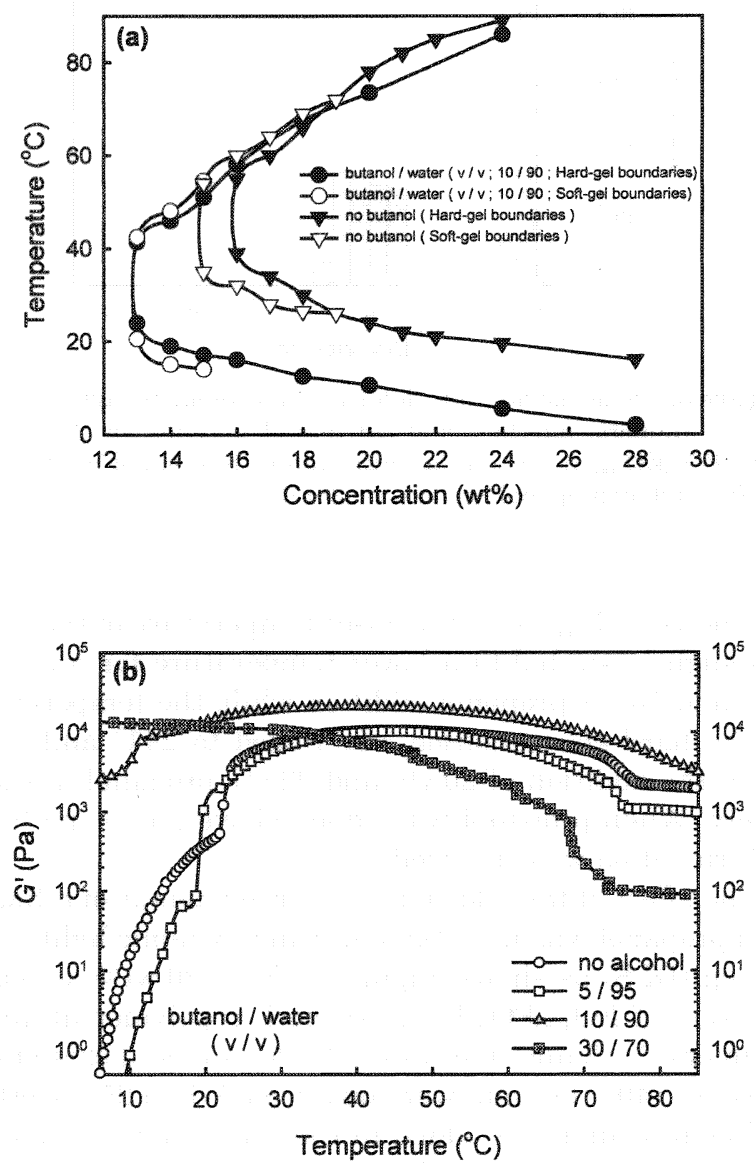

Figure 6. (a) Phase diagram of $\mathrm{EO}_{100} \mathrm{PO}_{65} \mathrm{EO}_{100}$ copolymer solution with $10 \mathrm{v} \%$ butanol in water compared with the phase diagram in pure water; (b) storage modulus $\left(G^{\prime}\right)$ plotted against temperature of $\mathrm{EO}_{100} \mathrm{PO}_{65} \mathrm{EO}_{100}$ copolymer with different volume fractions of butanol in water. The concentration of the copolymer was fixed at $20 \mathrm{wt} \%$ and heating rate was $1^{\circ} \mathrm{C} \mathrm{min}^{-1}$. shorter chain alcohol added. These effects are interpreted in terms of the disruption of water structure around micelles. ${ }^{31}$ Methanol and ethanol normally act as water-structure-breakers prevent the self-hydration of
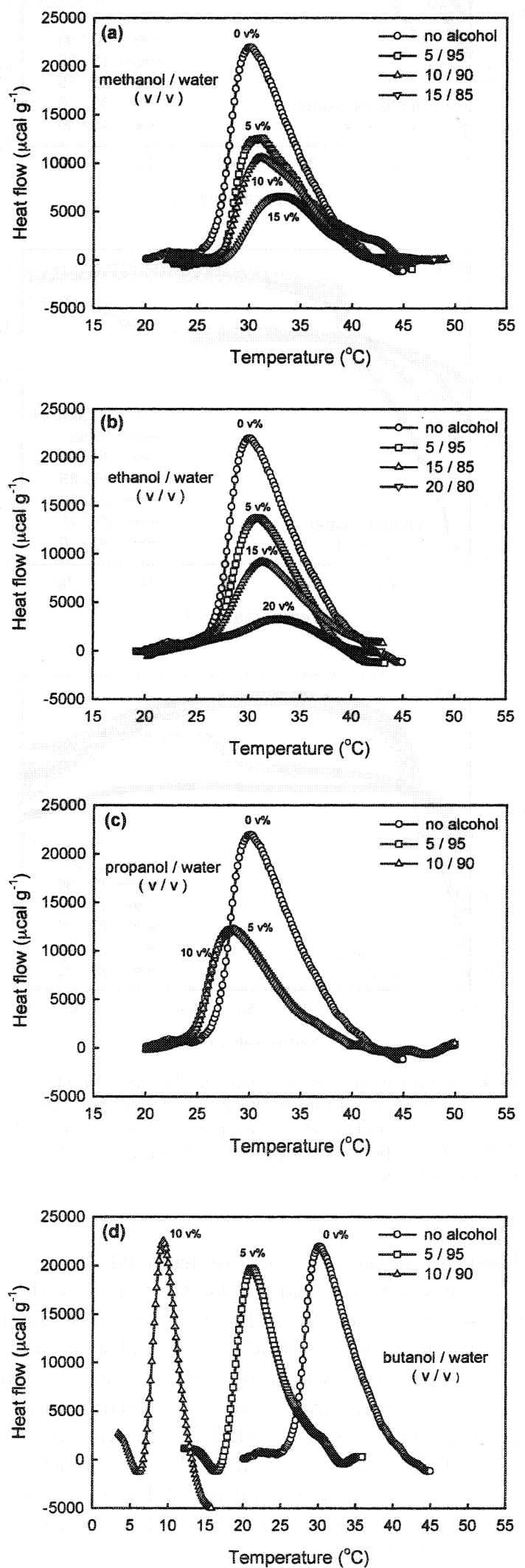

Figure 7. Scanning microcalorimetric measurement results on a $\mathrm{EO}_{100} \mathrm{PO}_{65} \mathrm{EO}_{100}$ copolymer at $0.3 \mathrm{wt} \%$ with different alcohols in water; for (a) methanol, (b) ethanol, (c) propanol, and (d) butanol. 

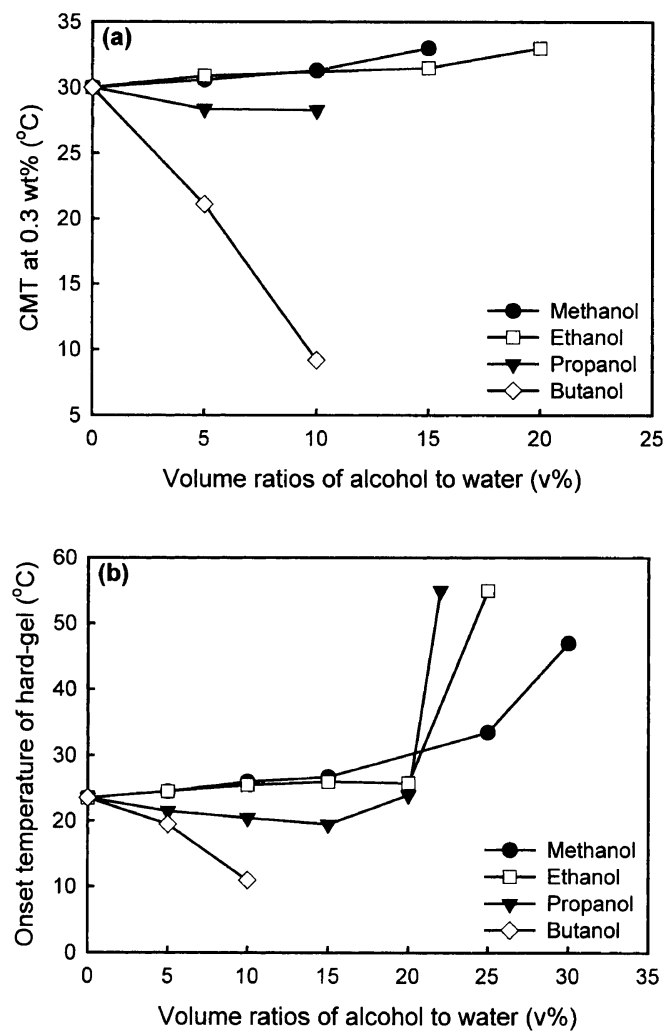

Figure 8. (a) Plots of cmt measured by microcalorimetry; (b) plots of onset temperature of hard-gels obtained from rheometry as a function of volume fraction of alcohol in water for different alcohols.

water, resulting in increased polymer solubility. These alcohols can be regarded as ligands which substitute water molecules in solvation. ${ }^{32}$ As a result, these alcohols bind to copolymer molecules in the same way as inorganic ligands bind to metal ions in coordination compounds. ${ }^{31}$ Propanol has a unique effect on $\mathrm{cmt}$ so much like the results in rheological properties. As shown in Figure 7c, the slightly lower cmt implies favorable formation of micelles while a reduced endotherm indicates decreased number of micelles upon the addition of the propanol. These seemingly contradictory results may be due to marginal alkyl chain length of propanol.

In the addition of longer chain alcohols such as butanol, cmt decreases with the amount of butanol and, at the same time, the endotherms are almost constant with the addition of butanol, as shown in Figure 7d. This effect of butanol addition on $\mathrm{cmt}$ is believed to occur because butanol acts as a water-structure-maker promoting the self-hydration of water by favorable interactions between butanol and water resulting in the exclusion of the copolymer in the solvent region and/or because butanol favors the aggregated form of the copolymer. ${ }^{31} \mathrm{Be}-$ cause gelation of the $\mathrm{EO}_{100} \mathrm{PO}_{65} \mathrm{EO}_{100}$ (Pluronic F127) copolymer in aqueous solution is mainly due to close packing of spherical micelles, ${ }^{1,15}$ the effects of different alcohols on micellization can be applied to the gelation. Since methanol and ethanol prevent micellization as shown in microcalorimetry, these alcohols suppress the gelation of copolymer solution. In contrast, butanol enhances micellization and gelation of the copolymer solution. As noted from Figures $8 \mathrm{a}$ and $8 \mathrm{~b}$, cmt and onset temperature of hard gels shift to higher values with increase in methanol or ethanol in the alcohol/water mixture while $\mathrm{cmt}$ and onset temperature of hard gels move to lower values in butanol/water mixed solvents.

\section{CONCLUSION}

TIM, rheometry, dynamic light scattering (DLS), and microcalorimetry were used to study the effects of alcohol addition on sol-to-gel transition and micellization of $\mathrm{EO}_{100} \mathrm{PO}_{65} \mathrm{EO}_{100}$ triblock copolymer, Pluronic F127, in water. Alcohols with shorter alkyl chains such as methanol and ethanol increased hard gel temperature and cmt. These effects are believed to occur because methanol and ethanol act as water-structure-breakers resulting in increased polymer solubility. The micellization of the $\mathrm{EO}_{100} \mathrm{PO}_{65} \mathrm{EO}_{100}$ triblock copolymer solution is thus suppressed and these effects can be applied to hard gel transition because hard gels form simply due to close packing of spherical micelles. Butanol acts as a waterstructure-maker resulting in exclusion of the copolymer or favors the aggregated form of the copolymer. Thus, the hard gel transition temperature as well as cmt are lowered by the addition of butanol. Since propanol has a marginal length of alkyl chain between ethanol and butanol, its effect on gelation and micellization may also be marginal.

Acknowledgment. We are very grateful for the financial aid from the Ministry of Education of Korea through the Brain Korea 21 Program at Seoul National University.

\section{REFERENCES}

1. K. Mortensen, W. Brown, and B. Norden, Phys. Rev. Lett., 68, 2340 (1992).

2. K. Mortensen, W. Brown, and E. Jorgensen, Macromolecules, 28, 1458 (1995).

3. K. Mortensen and J. S. Pedersen, Macromolecules, 26, 805 (1993).

4. R. K. Prud'homme, G. Wu, and D. K. Schneider, Langmuir, 12, 4651 (1996).

5. G. Wu, B. Chu, and D. K. Schneider, J. Phys. Chem., 99, 5094 (1995).

6. O. Glatter, G. Scherf, K. Schillen, and W. Brown, Macromolecules, 27, 6046 (1994).

7. B. Chu, Z. Zhou, and G. Wu, J. Non-Cryst. Solids, 172-174, 1094 (1994).

8. P. Alexandridis, J. F. Holzwarth, and T. A. Hatton, Macromolecules, 27, 2414 (1994).

9. R. J. Holland, E. J. Parker, K. Guiney, and F. R. Zeld, J. Phys. Chem., 99, 11988 (1995).

10. S. Hvidt, E. B. Jorgensen, W. Brown, and K. Schillen, J. Phys. Chem., 98, 12320 (1994).

11. J. Armstrong, B. Chowdhry, R. O'Brien, A. Beezer, J. Mitchell, and S. Leharne, J. Phys. Chem., 99, 4590 (1995).

12. B. Nystrom, H. Walderhaug, and F. K. Hansen, J. Chem. Soc., Faraday Discuss., 101, 335 (1995).

13. B. Nystrom and A. L. Kjoniksen, Langmuir, 13, 4520 (1997).

14. P. Bahadur and K. Pandya, Langmuir, 8, 2666 (1992).

15. G. Wanaka, H. Hoffmann, and W. Ulbricht, Colloid Polym. Sci., 268, 101 (1990).

16. R. G. Laughin, "The Aqueous Phase Behavior of Surfactants," Academic Press, Ltd., London, 1994.

17. M. Malmsten and B. Lindman, Macromolecules, 25, 5440 (1992).

18. G. E. Yu, Y. Deng, S. Dalton, Q. G. Wang, D. Attwood, C. 
Price, and C. Booth, J. Chem. Soc., Faraday Trans., 88, 2537 (1992).

19. J. Godward, F. Heatley, and C. Booth, J. Chem. Soc., Faraday Trans., 91, 1491 (1995).

20. J. Rassing and D. Attwood, Int. J. Pharm., 13, 47 (1983).

21. M. Vandere, G. L. Amidon, S. Lindenbaum, and J. L. Haslam, Int. J. Pharm., 22, 207 (1984).

22. H. Li, G. Yu, C. Price, C. Booth, E. Hecht, and H. Hoffmann, Macromolecules, 30, 1347 (1997).

23. M. Almgren, J. Van Stam, C. Lindblad, P. Li, P. Stilbs, and P. Bahadur, J. Phys. Chem., 95, 5677 (1991).

24. P. Holmqvist, P. Alexandridis, and B. Lindman, Langmuir, 13, 2471 (1997).
25. Y. Cheng and C. Jolicoeur, Macromolecules, 28, 2665 (1995).

26. R. Zana and M. J. Eljebari, J. Phys. Chem., 97, 11134 (1993).

27. A. Caragheorgheopol, H. Caldararu, I. Dragutan, H. Joela, and W. Brown, Langmuir, 13, 6912 (1997).

28. G. Wanaka, H. Hoffmann, and W. Ulbricht, Macromolecules, 27, 4145 (1994).

29. C. Y. M. Tung and P. J. Dynes, J. Appl. Polym. Sci., 27, 569 (1982).

30. B. Nystrom and H. Walderhaug, J. Phys. Chem., 100, 5433 (1996).

31. J. Armstrong, B. Chowdhry, J. Mitchell, A. Beezer, and S. Leharne, J. Phys. Chem., 100, 1738 (1996).

32. W. E. Waghorne, Chem. Soc. Rev., 22, 285 (1993). 